\title{
Effect of Individual Difference on Primary School English Education
}

\author{
Huiping Ma
}

\author{
School of Foreign Studies, Xi'an University, Shaanxi 710065, China
}

\begin{abstract}
Keywords: Primary school English Education; English learning; Individual difference
Abstract. There is no doubt that the core notion of the education is human-orientation. At the same time when the progress of overall plan in teaching activities is focused, the development of individual student should be taken into consideration as well, which is determined by the phenomenon of students' individual difference. As far as the primary school English education be concerned, the level of grasping a language by different children shows a significant difference. However, the problem of which the teachers confront, is how to integrally improve the teaching level and in the meantime, to effectively facilitate the development of each student. In terms of how to cope with the individual difference in teaching, the first thing we will consider is to teach students in accordance with their aptitude. Nevertheless, there are also a plenty of difficult problems when the strategy by teaching students in accordance with their aptitude is adopted. This study analyzed each variable existing in individual difference, cognitive characteristics of primary school students and the current situation of primary school English education, and based on which we come up with the strategy by teaching students in accordance with their aptitude. Under a premise of focusing the subjectivity of primary student, we are looking for a new teaching strategy that exceeds the students' individual difference.
\end{abstract}

\section{The definition of individual difference and the main variables}

The definition of individualdifference. Individual difference is also referred to as respective difference, which means that the psychological and physiological characteristics that are showed in the process of some psychological activities by individuals such as cognition, emotion and will are relatively stable yet different from those of others. It means the difference of psychological and physiological characteristics and the difference of behaviors caused by it. On the other hand, it means the difference of developing speed and level for each person.

Four kinds of individual difference. Regarding to the English learning, there are four major aspects of students' individual difference, which are the awareness and development of language, interest and motivation of study, study strategy and method and the factors of emotion.

The difference of awareness and development of language. Language study is a kind of practical activity. The ability to absorb and apply the language by each student is different. On one hand, it involves the base of cultural knowledge. on the other hand, it relates to the level of students' brain and thought development as well. The developing stage of language by each student is different, and the developing progress of language is different as well, which leads to the difference of awareness and development of language to student.

The difference of the study interest and study motivation. The study motivation can be known as the reason why we need to study. However, study interest means how much passion the students have when they are studying. There is a strong correlation between study interest and study motivation. And normally it is found to be positive correlation between them. Students with good study motivation will usually have higher study interest.

There are quite a lot factors effecting the study motivation, which include the level of cognition and the method of cognition as well. Different students have different method of cognition, and their level of cognition is diverse as well, which leads to the individual difference in terms of their study motivation. The environment of study and task of study will also affect the study motivation and 
interest of a student. For example, the nice environment of study can motivate the study motivation of a student, however, an extremely difficult task will defeat student's study interest.

Non-intelligent factor will also affect the study motivation of students, such as an award and praise from teachers, which can motivate the study motivation of students. One of the source that can also produce study interest and study motivation for students is teacher's consideration and care. In addition, confidence and sense of achievement can motivate the study motivation of students as well, and they can create better study interest. In terms of primary school student, the effect of these factors is more obvious. Primary school student with a higher level of cognition will have study motivation due to the ambition of a good score. Most of the primary school students have study motivation for the reason that they can get appreciation and love from their teachers and parents. Nevertheless, their study interest, to a great extent, is decided by the effect of classroom teaching. The boring and dull teaching method will not be able to create study interest for them. And the unchanging teaching habits will make it hard for them to keep their study interest. In addition, different family environment is also the reason leading to the difference of their motivation and interest. Given that the presence of the various effected variables mentioned above, there is a significant difference present in the study motivation and study interest of primary school students.

The difference of study strategy and method. In terms of the way to understand and grasp knowledge, different students will adopt different method and way, and their study plan and procedure are diverse as will, and they have different study habits, which are the reason for the difference of their study strategy and method. It is necessary to focus on a teaching principle that teacher should emphasize the role of student as the main body in education, encourage students to form the habit of learning independently and encourage them that they can find a suitable study goal and method according to their own ability. Regarding to the primary school English education, each student has different ways to grasp and practice a language. Taking reciting text as an example, some students prefer to read loudly then memorize, while some students tend to recite silently by heart. Another case is that, considering the application of a language, some students like to make sentences and prefer the practice of substitution, while other students tend to perform the sentences learned before. There are students who will over rely on teachers. They show obvious dependence and passiveness in terms of acquiring and application of a language.

The effect of study strategy and method on the school record is significant. Study method with high efficiency will undoubtedly lead the student beyond the acquiring of knowledge. While low-efficiency and laggard study method will undoubtedly slow down the progress of acquiring a language. It is obviously that teacher will encourage more better study method, but it is not easy for each student to accept with pleasure and keep. As for those students with high passiveness, the carelessness and blindness of them in learning English are quite strong. These kinds of students normally lack a good study plan and certain study goal. Their way of studying usually is by taking instead of learning. Reading and listening to English is much more than actively speaking English.

Usually, students can improve their own study strategy and method by learning from each other. Teachers always encourage in terms of that. However, given that there is individual difference, students will finally get used to their own study method as the result of so many various factors such as the level of the development of cognition, personality, habits and environment of study, and so on.

The difference in terms of emotion. Emotional factor, to a great extent, shows the individual difference in learning English. The emotion of some students tends to more positive. They act actively, optimistically, confidently and bravely. Most of the performance of these kinds of students in or out of the English class is quite active. They will have more passion when they study, and they have more chance to study and practice English. Positive emotion can help the for better school record in a way, and the sense of achievement will in a contrary provide them more strong study motivation and constant study interest. The appreciation from teachers and parents and the admiration from classmates will enhance their positive emotion as well. In a contrary, other parts of students tent to more negative in emotion, which is a big reason leading to negative effect on their English study. For example, they will hold back and show less confidence in classroom activities, and 
they are extremely unconfident when taking challenge and tasks. They fail to correctly accept the remind from teachers and the criticism from classmates. They will face their shortage and mistakes with negative and resistant emotion instead of positive and regret emotion. All these factors result that their emotion is always in the situation of repression when they study. In addition, English learning is a kind of social practice activity. Students with introverted personality do not like to social, so they will possibly be good at listening and writing, but they are quite passive in speaking and expressing. Students with outgoing personality prefer to speak and act. They like to answer questions and take part in activities, while they are not that stable and quire in terms of study. All these emotional factors show the individual difference, and they influence the primary school English education in various aspects.

\section{The effect of individual difference on primary school English education}

The characteristics of cognition development of primary school student. InChina, most of primary school students start learning English in their third grade which is the stage of primary school students' middle and high academic year. In this stage. The characteristics of cognition development of primary school students are as follow.

First of all, in terms of the attention, primary school students 'unconscious attention has been already mature from lower grade. Something that can attract unconsciously the attention of adult can also attract these kinds of students. The unconscious attention is the main type of attention of them, among which attach to obvious emotional color. As we usually know, emotion of a child is expressed on their faces, and the contents that attract their attention are always visual and vivid, which in other words, makes it very important for teachers to create the external teaching environment. When it comes to higher grade, primary school students' conscious attention has gradually developed. They have a better understanding to the significance of learning and their own responsibilities, which in other words, is what we usually talked about, that they have grown up. At this point, they will appear to be more dependent and conscious to learn.

In terms of the stability of study attention, primary school students 'stability of attention remains in the constant developing process. Their higher neural system is still in the stage of growth. Their attention is easily distracted, which in other words means that they have low stability of attention and they fail to control themselves. Not because that they have too strong curiosity, the novel and sudden stimulation from outside will easily distract their attention. English learning is a comprehensive training by listening, speaking, reading and writing. Given that the distribution ability of attention from primary school students is quite low, what they can stably pay attention to is normally only one aspect of things. Therefore, to absorb the attention of students is one of the important factors in primary school English education that should be taken into great consideration.

Second, in terms of the ability of memorization, the method of memorization of primary school students from low grade mainly depends on mechanically retelling. While primary school students from high grade will apply some interesting memorizing method, such as low-level imagination, generalization and summarization, and so on.

The imaginal memory from primary school students from low grade is obviously better than the abstract memory. Their ability to memorize specific image is remarkably higher than the ability to memorize language. Although the ability of abstract memory from primary school students from high grade develops in a quick speed, which even passes the developing speed of specific imaginal memory, when they memorize something abstract, they still need to depend on specific objects.

Last but not least, regarding to the level of thinking, primary school students from low grade still in the stage of depending on specific image. While primary school students from high grade possess certain ability to summarize and abstract, who are in the shifting stage from specific image to abstract logical thinking. 
The analysis of current situationof primary school English education and the effect of individual difference. It is required by the teaching syllabus that the primary school English education should mainly focus on the development of interest. It sounds like a flexible teaching index, which results that most of the schools really pay less attention to the primary school English education.

At present, there are the following main characteristics of current situation of primary school English education. First of all, the class hour of primary school English education is less. Normally there are three English classed per week. The teaching hour is not enough, which helps nothing for teachers to solve the students' individual difference and teach by different level.

Second, listening and speaking are the main learning method of primary school English, but there is no relative training of pronunciation rules. The students do not understand the spelling rules of vocabulary, and do not realize that English can be written as Chinese alphabets. In other words, this is the reason why so many parents hope that the English teachers of primary school can teach the students of the phonetic symbol. Focusing on the activities of listening and speaking is relatively benefit in consideration to the individual difference during the learning of primary school students. However, when it comes to high grade, the spelling ability of primary school students is still very poor, it is not difficult to believe that they do not have enough support to their middle school English learning. And in terms of the utilization of education resources, it is actually a kind of waste.

Moreover, nowadays, the quality of primary school English teachers from many regions need to improve. Regarding to the appointment choice of employees, there appears to pay little attention to the ability of language knowledge, and high attention to the teaching skills. In terms of the effect of individual difference on education, the phenomenon that just let the situation be what it is, is quite normal. Lots of primary school English teachers spend no time and energy to study the interest of teaching, and when it comes to the different school records caused by individual difference of primary school students, these teachers take it for granted.

All in all, in view of the presence of individual difference, primary school students in the same class show different levels of English, which leads to the difference of their study interest towards English. Nevertheless, the purpose of English learning in the stage of primary school is to develop the students' study interest towards English. Having interest towards English learning earlier will not help a lot in their future development. On the other hand, facing with these students of different levels, teachers confront of a lot of difficulties in terms of organizing the teaching. Therefore, it is greatly necessary to study the way and strategy to reduce the effect of individual difference of primary school students on education.

\section{The teaching strategy when facing with individual difference of primary school students}

One point that should be confirmed firstly, is that the final goal of educationis not the delivery of knowledge, which is only the process and means during education. However, to improve the comprehensive development of a person is the essential goal of education, especially in the stage of primary school. As a consequence, the general policy to cope with individual difference of primary school students is to focus on the students' role as main body, active their dependence, develop and motivate their creation and lay a solid foundation to their constant comprehensive development.

Second, under the condition of a class with a large number of students, the balanced development of the whole and individual cannot be both taken into consideration. What needs to admit is, that even though the difference of developing level is caused by the individual difference between students, these students still have a lot of potential to be found. And the teachers should assist students to realize the development to their maximum extent based on their current levels.

Last but not least, it is necessary to set up the principle of comprehensive development. A primary school student is an individual in the development of formation of integrated personality. The primary school English education needs to pay attention to the comprehensive development of the knowledge, emotion and thought. The individual difference should not be the symbol of good or bad 
student for them. The task of primary school English education should go to that, students' advantages can play their best role and students' disadvantages can be recovered.

\section{Conclusion}

To cope with the individual difference, teachers play a vital role, as well as the mutual effort by students and parents. Teachers should play a direct role in teaching activities, observe and understand the levels of cognition development of primary school students. Through active and positive guide, teachers can motivate the study motivation and study interest of primary school students, help them with better learning method and study habits, create a teaching atmosphere that is full of positive energy, develop their positive and confident emotion and fully active their dependence in study. With the cooperation by parents, teachers can improve their teaching levels of primary school English education and facilitate the comprehensive development of primary school students.

\section{References}

[1] Ministry of Education. English Curriculum Standards. Beijing Normal University Publishing House: Beijing, 2001.

[2] Yang, J.L, The sharing of individual difference of students in education, China Science and Technology, (8), pp. 265, 2011.

[3] Shao, L.L, Back-to-basics approach in English classroom education - thinking of primary school English classroom, Keputonghua: New Classroom, (9), 2015.

[4] $\mathrm{Su}, \mathrm{J}$, Respect of individual difference, encourage students' personality - brief analysis of difference of primary school English education, Xinkecheng, (6), 2012. 